\title{
The effects of bilateral cingulate cortex lesions on morphine withdrawal symptoms in rats
}

\author{
CLINTON L. TRAFTON, LUCRETIA KOWALCZYK, and RICHARD MACLEOD \\ University of Arizona, Tucson, Arizona 85721
}

\begin{abstract}
In order to test the hypothesis that bilateral cingulate cortex lesions prevent opiate dependence and associated withdrawal symptoms, rats were given access to sucrose morphine solutions and subsequently challenged with nalorphine, an opiate antagonist. Animals with cingulate cortex lesions lost more weight following the nalorphine challenge than other animals, indicating that the lesions do not prevent withdrawal symptoms. On the contrary, the lesions are associated with more severe symptoms, and by inference, physiological dependence as well.
\end{abstract}

Cingulate cortex lesions are associated with decrements in morphine-oriented behavior by rats (Trafton \& Marques, 1971). Such decrements in morphine intake are shown both by animals premedicated with morphine injections and by animals that are not premedicated (Trafton \& Kahn, 1974). However, the mechanism whereby cingulate cortex lesions reduce morphine intake remains obscure. One explanation is that cingulate lesions render the pleasurable or positive reinforcing effects of morphine intake less"intense, thus reducing the animal's consumption. An alternative argument is that, at least among premedicated animals, cingulate cortex lesions somehow prevent physiological dependence and, thus, withdrawal symptoms as well. Morphine intake, according to the latter argument, is at least in part the dependent animal's method of avoiding withdrawal symptoms. Thus, if lesions prevent withdrawal symptoms, morphine intake would be unnecessary.

The present study was designed to test the hypothesis that bilateral cingulate cortex lesions prevent physical dependence and withdrawal symptoms in rats. Following the procedure of Risner and Khavari (1973), oral ingestion premedication is followed by nalorphine challenge. Rats subjected to such conditions show severe weight loss due to diarrhea during the 48-h period after nalorphine injections and that weight loss is taken as an index of physiological dependence. Presumably, the diarrhea is one uncomfortable symptom among others associated with opiate withdrawal.

\section{METHOD}

\section{Subjects}

The subjects were 30 male albino rats of the Sprague-Dawley strain, weighing between 216 and $350 \mathrm{~g}$ at the beginning of the

Requests for reprints should be sent to Clinton L. Trafton, Department of Psychology, University of Arizona, Tucson, Arizona 85721. This research was supported in part by Public Health Service Grant No. 1-RO1-MH20971-02. experiment. Each rat was housed individually and had ad-lib access to Purina Rat Chow throughout the experiment. Drinkíng solutions were provided in $100-\mathrm{ml}$ graduated glass drinking tubes mounted on the front of the cages.

\section{Surgical Procedure}

The rats were randomly assigned to three groups of 10 each. Group CM (Cingulate-Morphine) received bilateral anterior cingulate cortex lesions. Sodium pentobarbital anesthesia $(35 \mathrm{mg} / \mathrm{kg}$, IP) was induced $1 / 2 \mathrm{~h}$ after atropine sulfate injections (1 cc) which were given to reduce respiratory tract secretions. The bilateral anterior cingulate cortex lesions were made electrolytically through closely spaced holes drilled in the skull $.6 \mathrm{~mm}$ lateral from the midline. A current of $1.0 \mathrm{~mA}$ was applied for $15 \mathrm{sec}$ at each electrode site. The lesion targets extended $5.5 \mathrm{~mm}$ anterior from the bregma and were designed to fuse to produce a continuous ablation of the anterior midline cortex. Group NCM (No Cingulate-Morphine) received sham operations. They were anesthetized, and skull holes were drilled as for Group CM, but no lesions were introduced. Group $S$ (Sucrose) received no surgical treatment.

\section{Procedure}

Two weeks after the lesions were given, the water bottles were removed from the cages, and Groups CM and NCM were given bottles containing $1.0 \mathrm{mg}$ of morphine $\mathrm{HCl}$ per milliliter of $10 \%$ sucrose solution. Group S received $10 \%$ sucrose only. No other fluids were available, and Groups CM and NCM were thus forced to consume morphine. Daily measurements of food, fluid intake, and body weight were recorded for 21 days. On the 21 st day of the experiment, all rats were given a $16-\mathrm{mg} / \mathrm{kg}$ intraperitoneal injection of nalorphine. Food intake, liquid intake, and body weight were measured at 0 (baseline), $4,8,24$, and $48 \mathrm{~h}$ after the nalorphine injection. Ad-lib access to the sucrose morphine and sucrose solutions for the experimental and control groups, respectively, was maintained throughout these tests. Following these tests, the rats in Group CM were killed; their brains were perfused with saline and Formalin, sectioned and stained with cresyl violet, and inspected to assess brain damage.

\section{RESULTS}

Seven rats died during the experiment. Two rats were from Group CM, while five rats were from Group NCM. The deaths were preceded and probably caused by a refusal to drink the only available fluid, sucrose morphine, and a subsequent decrease in body weight. No rats in Group S died. 


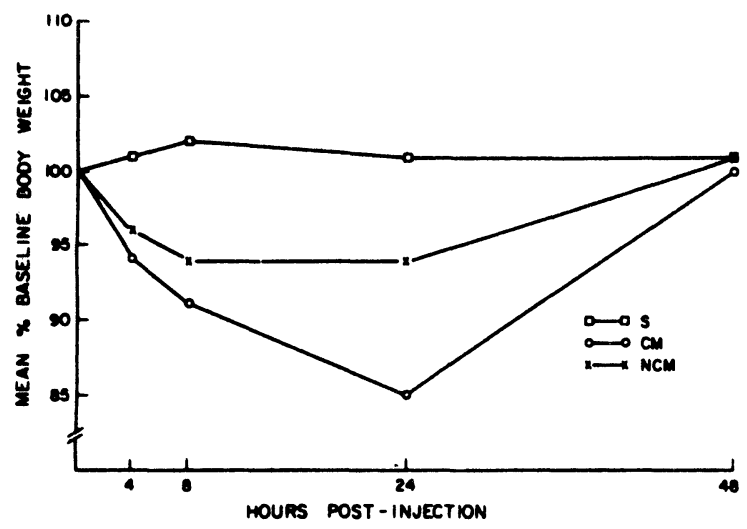

Figure 1. Mean body weight ( $\%$ of baseline) following $16 \mathrm{mg} / \mathrm{kg}$ nalorphine injections.

After perfusion of the Group CM brains, observations showed that three of the brains did not have visually detectable anterior cingulate cortex lesions. The three rats were thus considered to belong to the NCM group. So, finally, five rats remained in Group CM, eight rats comprised Group NCM, and Group S had 10 rats.

Group CM lost more body weight after the nalorphine injection than either Group NCM or Group S. Figure 1 shows the mean percentage of baseline body weight (weight at time of nalorphine injection) lost for the three groups at 4, 8, 24, and $48 \mathrm{~h}$ after the nalorphine injection. Group CM lost weight steadily until $24 \mathrm{~h}$ after the nalorphine injection; by $4 \mathrm{~h}$ postinjection, they had lost $6 \%$ of baseline weight. Eight hours after the injection, $9 \%$ of baseline weight had been lost. Twenty-four hours postinjection, $15 \%$ of mean body weight was lost. There was a return to baseline body weight at $48 \mathrm{~h}$ after the injection. Group NCM lost $4 \%$ of mean body weight $4 \mathrm{~h}$ after the nalorphine injection. At 8 and $24 \mathrm{~h}$ after injections, their weight loss was constant at $6 \%$ before returning to baseline. Group CM lost significantly more weight $24 \mathrm{~h}$ after nalorphine injections than either other group $(\mathrm{p}<.05)$ and lost significantly more weight than Group $S$ at 4 and $8 \mathrm{~h}$ postinjection, as well $(p<.05)$. No significant differences between any groups were found either at

Table 1

Intake of. Food and Fluids Following Nalorphine Injections (Percentage Baseline)

\begin{tabular}{lccccc}
\hline & \multicolumn{4}{c}{ Hours Following Injections } \\
\cline { 2 - 3 } \cline { 5 - 6 } Group & Food & Fluid & & Food & Fluid \\
\hline S & 86 & 91 & & 101 & 114 \\
NCM & 93 & 62 & & 125 & $175^{*}$ \\
CM & 63 & 45 & & 126 & 131 \\
\hline
\end{tabular}

$* p<.05$ relative to Group $S$ baseline or at $48 \mathrm{~h}$ postinjection. Wilcoxon-MannWhitney tests were used on all comparisons.

Baseline weight and intake measures were defined by the averages obtained during Days 19, 20, and 21 of the preinjection period.

Analysis of the food and fluid intake data during the first 24-h period following injections reveals that there were no statistically significant differences between the groups for food or fluid intake. However, as Table 1 shows, Group NCM drank a significantly greater amount of fluid than Group $S$ at $48 \mathrm{~h}$ postinjection.

The lesions induced were extensive in all five rats of Group CM. Most of the midline tissue from the anterior pole to the genu of the corpus collosum was destroyed, with the lesions extending about $1 \mathrm{~mm}$ lateral to the midline and from 2 to $4 \mathrm{~mm}$ below the dorsal surface of the cortex including the pre- and subgeneral areas. One rat received damage to the corpus collosum and dorsal septum as well.

\section{DISCUSSION}

Cingulate cortex lesions do not lessen morphine dependence or withdrawal symptoms in rats. On the contrary, among rats with extensive morphine intake experience (Groups CM and NCM), the animals with lesions tend to lose more weight following nalorphine challenge than nonlesioned rats. Thus, the effectiveness of cingulate cortex lesions in reducing voluntary morphine intake (Trafton \& Kahn, 1974; Trafton \& Marques, 1971) cannot be explained by the absence of dependence and associated withdrawal symptoms.

The present results, coupled with those of Trafton and Kahn (1974) showing decreases in morphine ingestion by cingulate-lesioned but drug-naive rats, seem most compatible with the argument that such lesions reduce the pleasurable or positively reinforcing effects of morphine.

\section{REFERENCES}

Risner, M., \& Khavari, K. Morphine dependence in rats produced after five days of ingestion. Psychopharmacologia, 1973, 28, 51-62.

Trafton, C. L., \& KAHN, M. Effects of cingulate cortex lesions and morphine premedication on morphine intake in rats. Physiological Psychology, 1974, 2, 26-30.

Trafton, C. L., \& Marques, P. R. Effects of septal and cingulate cortex lesions on opiate addiction behavior in rats. Journal of Comparative and Physiological Psychology, 1971, 75, 277-285.

(Revision received for publication September 21, 1975; accepted October 17, 1975.) 